\title{
Health and Safety Management Practices in the Building Construction Industry in Akure, Nigeria
}

\author{
Olusoga Olawale Oreoluwa*, Fagbemi Olasunkanmi \\ Department of Architecture, Federal University of Technology, Akure, Nigeria \\ Email address: \\ waleolusoga@yahoo.com (O. O. Oreoluwa),summex2003@gmail.com (F. Olasunkanmi) \\ ${ }^{*}$ Corresponding author
}

\section{To cite this article:}

Olusoga Olawale Oreoluwa, Fagbemi Olasunkanmi. Health and Safety Management Practices in the Building Construction Industry in Akure, Nigeria. American Journal of Engineering and Technology Management. Vol. 3, No. 1, 2018, pp. 23-28.

doi: 10.11648/j.ajetm.20180301.12

Received: January 27, 2018; Accepted: February 11, 2018; Published: March 14, 2018

\begin{abstract}
Health and safety of construction workers on building construction sites in Nigeria have become necessary as a result of the hazardous nature of the practice. It is noteworthy to mention that accidents of any kind are bound to happen on these sites resulting into injuries that are sometimes fatal to site workers. Nevertheless, an evaluation of the health and safety management practices put in place by building contractors in the construction industry in Nigeria is the main thrust of this study. This paper discusses the different sources of accidents on construction sites. It also investigates the current state and adherence to health and safety practice in Nigeria. 110 questionnaires were used to extract information from respondents within the Akure metropolis. The safety precautions put in place by contractors for their site workers was also probed. Issues such as the post-accident treatment of site workers were also investigated. Data collected were analysed using descriptive statistics. The study found that construction workers are left to protect themselves in the line of duty and are largely responsible for any occurrence of accidents. As a result, a lot needs to be done to ensure the health and safety of site workers. Recommendations were made on possible solutions yearning for strict actions to be taken against defaulters by the respective site inspectors.
\end{abstract}

Keywords: Construction, Health, Management Practice, Safety, Site Workers

\section{Introduction}

The construction industry in Nigeria has since being on a steady rise in recent years owing to the large expanse of undeveloped Land required to provide shelter for the booming population. As a result, the population of construction workers has also soared. The building construction industry is made up of different personnel having different trades to handle different construction process. Bala et al. [4] cited large number of seasonal migrant as one of the several reason for this growth in population because many of them are ignorant of construction processes. With this increase both in terms of development as well as personnel comes an increase in site accidents. According to Smallwood et al 2008, the construction industry has earned a reputation of being a dangerous or highly hazardous industry because of the disproportionately high accidents and fatalities that occur on the construction sites around the world. The International Training Centre of the International Labour Organization claims that one in six fatal accidents at work occur on a construction site .

Health and safety is of extreme importance within the construction industry as different construction operations take place at about the same time. This can be attributed to building project delivery dates agreed upon during bidding for construction jobs by building contractors. Health and safety is relevant to all branches of industry, a practice that is particularly imperative for the construction industry [1]. In advanced countries of the world, visibly improvements have since been made to mitigate site accident. This in turn cannot be completed said of Nigeria as the industry is blighted by reports of accidents on construction site with even the multinational companies falling prey of such distasteful occurrence. Construction managers over time have devised a cheaper means of employing laborers on casual or temporary 
basis. This is partly because they are not tied to any permanent employment contract which strips them of any benefit from the company or employer in term of insurance. As a result, the contractors do not feel responsible for any unfortunate occurrence in term of accidents that eventually befall the laborers. This in turn affect the productivity of such laborers as issues of life is taken first before work hence the evident defect seen in workmanship output especially in the Nigeria building industry.

Information about accidents in the Nigerian construction industry is also not properly documented. This makes it an arduous task getting relevant data. This was stressed by Okeola [16] that because most contractors fail to report cases of accidents to the ministerial departments in charge of such occurrence, there are no reliable data. It has therefore become imperative to look into these accidents as it has over time rendered site laborers useless to themselves and the society due to the extent of this injuries sustained in the line of duty. This was discussed further by Awodele and Ayoola [3], Smallwood and Haupt [17] that not less than hundreds or construction workers are being killed each year and a much more maimed on construction sites in Nigeria. It has also in some extreme cases led to death as a result of the neglect of some construction managers' adherence to health and safety laws but in place. Construction site workers are often exposed to very risky job descriptions ranging from working at heights, welding, working underground, handling dangerous plants and equipment, drilling and handling fire cables.

Accidents on construction sites which are inevitable can be reduced to a bearable minimum if parameters are put in place and are strictly adhered to by all the parties involved. The training of site workers on the extreme importance of health and safety procedures is also essential to curb further sad tales of site accidents.

Building construction projects in Nigeria is characterized with swift project execution. Even with the use of modern day technology which involve the use of construction machines and mechanism, there is still a need to include manual labour in the building construction process. This paper aims at investigating the compliance of construction managers to health and safety management of their site construction workers in preventing accidents.

\section{Review of Literature}

Alhajeri [1] defined health as the protection of the body and mind from illness which results from the materials, processes or procedures used in the workplace. Health was also described as the protection of people from physical injury. The World Health Organization also defined health as a state of complete physical, mental and social well-being and not merely the absence of disease or infirmity. It can be seen from this definition that the issue of OHS in achieving a viable construction project is imperative.

\subsection{Accident Causation}

Several reasons can be seen as the cause of construction accidents which can be related to human behavior, environmental factors, mechanical factors as well as poor safety management. The dynamic nature of construction work happens to be one of the major causes for several types of accidents resulting to injuries and fatalities in the construction industry [6].

Accident is a phenomenon having several related definitions. According to Mwombeki [13], accident is viewed as an unplanned and unexpected occurrence that upsets a planned sequence of work thereby resulting to loss of production, injury to personnel, damage to plant and equipment as well as eventually interrupting production flow. Most authors see accident as an unplanned events leading to injury either fatal or minimal which in turn disrupt work and often times bring about loss of business opportunities. Accidents which results in both direct and indirect cost does not necessarily have to be injurious or damaging but can interrupt the completion of an activity [16]. It goes to show that regardless of how careful one can be, accidents are bound to happen. In the process of cutting cost and making decent gain on a building construction site, use of standard equipment are often compromised and this has led to the death of many.

Accident causation refers to factors which are responsible for accidents and therefore, understanding what causes unsafe situations to occur is important in implementing measures to help prevent reoccurrence. Elimination of accident causation can drastically eliminate hazards and this was stressed by Walah [18] that this accidents can be rectified by the workers abiding by the rules and regulations in respect to the happening.

\subsection{Safety Culture}

Safety culture is held in high regard within the construction industry. It is described as the product of individual or group values, attitudes, perception and patterns of behaviour that determine the commitment to, and proficiency of an organizations health and safety management [19]. Zou et al. [22] defined safety culture also as an agglomeration of individuals as well as group that are concerned with abating the risks and exposure of workers and the public to unsafe acts and conditions in a construction environment. This goes to show that for an effective safety culture, all organization members must share a set of belief about risk as well as accidents. Culture is seen to have a hand in accident causation which is predicated on the obvious migration of construction workers across developed countries of the world. This was stressed by Balch and Geddes [21] that a structurally embedded reliance on cheap and flexible sources of regularly and irregularly employed migrant workers has always been a key feature of the UK construction sector. The way of life of people differ from place to place which in turn take its toll on construction work. Alhajeri [1] opined that the importance of culture to 
health and safety management cannot be overemphasized because it does help in understanding the different approaches to accident prevention. The different characteristics that help to identify culture which ranges from; Culture being a system of values, Culture influencing beliefs, attitudes, perception, and behavior, and Culture distinguishing one group from another.

Accident causes are ironically known to all building construction employers and also almost preventable but as other business issues, occupational safety and health can be managed in the enterprise; [8]. Human factors, Mechanical factors, and Environmental factors are also seen to be important factors that causes accident. It can be seen as discussed by several authors that the issue of OHS encompasses a whole lot which is not limited to wearing Personal Protective Equipment alone. It is a philosophy that discourages work practices that place individuals at risk of injury and the integration of Health and safety into the daily work process [1]. Construction accidents according to the Workmen's compensation decree of 1987 include but not limited to; Permanent partial incapacity, Permanent total incapacity, Temporary incapacity and Fatal accidents, where death results.

\subsection{Health and Safety Procedures Available in Nigeria}

Compensation of workers discusses basically the insurance policy covering injuries sustained by workers on site. It includes a collection of laws that states clearly benefits injured employees are entitled to in the case of occurrence of any accidents during working hours [20]. Compensation programs were designed to reduce litigation for work-related injuries, illness and death. The legislations on Health and safety in Nigeria building construction industry include but not limited to; Labour Act of 1974 modified to Labour Acts 1990, and updated to Labour Act, Cap L1, Laws of the Federation of Nigeria (LFN), 2004; the Factories Act of 1987 which became effective in 1990 and later updated to Factories Act, Cap. F1, LFN, 2004; the Workman's Compensation Act of 1987 which became effective in 1990, modified to Workman's Compensation Act, Cap W6, LFN, 2004 and repeal to Employee's Compensation Act, No. 13, 2010 of the laws of the Federation of Nigeria, the Insurance Act, 2003 and the Labour, Safety, Health and Welfare Bill of 2012. The National Building Code which is about the worst case scenario that after being approved by the National executive council in 2006 is yet to be enforced. In advanced countries of the world, legislation issues of occupational health and safety (OHS) are taken seriously. That does not neglect the fact that such laws are also in existence in Nigeria but laws or regulations made without proper enforcement is no law at all [2]; [7].

\section{The Study Population and Study Area}

Akure, the study area which is a city in south-western Nigeria is the capital of Ondo State. The total area is approximately $41.2 \mathrm{~km}^{2}$ and it lies on a relative plain of about
$250 \mathrm{~m}$ above the sea level. Akure lies about $70^{\circ} 15^{\prime}$ north of the equator and $50^{\circ} 15^{\prime}$ east of the Meridian. The town is situated in the tropic rainforest zone in Nigeria. The last census conducted in 2006 put the city's population at 484,798 i.e. Four hundred and eighty four thousand, seven hundred and ninety eight (NPC, 2006). Akure, the study area which is a city in south-western Nigeria is the capital of Ondo State. The total area is approximately $41.2 \mathrm{~km}^{2}$ and it lies on a relative plain of about $250 \mathrm{~m}$ above the sea level. Akure lies about $70^{\circ} 15^{\prime}$ north of the equator and $50^{\circ} 15^{\prime}$ east of the Meridian. The town is situated in the tropic rainforest zone in Nigeria. The last census conducted in 2006 put the city's population at 484,798 i.e. Four hundred and eighty four thousand, seven hundred and ninety eight (NPC, 2006).

The easiest way of solving a problem is by identifying its source. It has become necessary to identify the type of construction work obtainable in the study area. Kadiri et al. [11] categorized construction activities in F.C.T. Abuja into; Multinational Construction Companies, Large scale indigenous construction companies and Small scale indigenous construction companies. It is important to stress that the small scale indigenous construction enterprises are the most predominant in the city of Akure which according to Kadiri et al. [11] engage mainly in construction of residential and commercial buildings with site offices or buildings and no headquarters but offices. The major essence of these companies is to maximize profit in whatever form possible.

\section{Methodology}

Relevant data was extracted for this study through the use of structured questionnaires within the study area on frequency of construction work, insurance scheme available and compensation packages accessible to construction workers. The population of the study was construction workers operating small scale indigenous construction companies within Akure. The target respondents consisted of Architects, Engineers, Building contractors, Project managers and Quantity surveyors. 150 questionnaires were distributed to these target respondents and a total of 110 questionnaires were completed and returned which constitutes $73.3 \%$ while the information retrieved were analyzed with the aid of descriptive analyses tools.

\section{Result and Discussion}

Summarized in Table 1 are the characteristics of respondents in Akure. These include their sex, Level of education, specialization in the building industry and period of practice experience.

The gender of the respondents was predominantly dominated by the male with $79.1 \%$ while the female gender completed the remaining 20.9\%. However, the highest level of education of the respondents in the table below shows that construction within the study area is dominated by the Higher National Diploma holders with $50.0 \%$. Investigation into the specialization of respondents in the building industry 
revealed that the Architects have the highest frequency $56(50.9 \%)$. The practice experience of respondents also indicates $55(50 \%)$ of them have between $6-10$ years practice experience.

Table 1. General information of respondents.

\begin{tabular}{lll}
\hline Sex & frequency & Percentage \\
\hline Male & 87 & 79.1 \\
Female & 23 & 20.9 \\
Total & 110 & 100 \\
Level of education & frequency & Percentage \\
OND & - & 0 \\
HND & 55 & 50.0 \\
B.Sc. & 38 & 34.6 \\
M.Sc. & 15 & 13.6 \\
Ph.D. & 2 & 1.8 \\
Total & 110 & 100 \\
Specialization in the building industry & frequency & Percentage \\
Architect & 56 & 50.9 \\
Engineer & 33 & 30.0 \\
Builder & 13 & 11.8 \\
Project Manager & 8 & 7.3 \\
Quantity Surveyor & - & 0 \\
Total & 110 & 100 \\
Period of practice experience & frequency & Percentage \\
0-5 years & 32 & 29.1 \\
6-10 years & 55 & 50.0 \\
11-20 years & 23 & 20.9 \\
Over 20 years & - & 0 \\
Total & 110 & 100 \\
\hline
\end{tabular}

Data on respondents' participation in construction work shows that a total of $45(40.9 \%)$ respondents participates frequently in construction while 28 (25.5\%) are predominately involved in building construction, $25(22.7 \%)$ rarely do and a total of $12(10.9 \%)$ do not participate in construction at all.

Table 2. Participation of respondents in construction

\begin{tabular}{lll}
\hline $\begin{array}{l}\text { Participation in construction } \\
\text { work }\end{array}$ & frequency & Percentage \\
\hline Not at all & 12 & 10.9 \\
Rarely & 25 & 22.7 \\
Frequently & 45 & 40.9 \\
Always & 28 & 25.5 \\
Total & 110 & 100 \\
\hline
\end{tabular}

The result of findings (Table 3) on employment status indicates that respondents prefer to employ construction workers on casual basis 56 (50.9\%). This implies that their employment is on temporary basis. A very low percentage $(10.9 \%)$ of workers are employed on the basis of full-time employment while $42(38.2 \%)$ are engaged on a daily pay basis. Respondents find it cheaper to employ either casual workers or recruit workers on daily pay basis because it makes them spend less and also they become less responsible for any form of accident that might occur. There is a difference to this assumption for the respondents who recruit workers on full employment basis, citing their reasons as; being able to monitor their state of mind when construction work is going on, cheaper and also being able to instill relevance of health and safety principle in them.
Table 3. Employment status of respondents.

\begin{tabular}{lll}
\hline Employment Status & frequency & Percentage \\
\hline Full-time & 12 & 10.9 \\
Casual worker & 56 & 50.9 \\
Daily & 42 & 38.2 \\
Total & 110 & 100 \\
\hline
\end{tabular}

The result obtained (Table 4) on compensation of site workers reveals that $75(68.2 \%)$ of respondents provide a form of compensation for their workers which include footing a large chunk of their medical bills when there is an occurrence of accidents on construction site, as against $35(31.8 \%)$ who provide no form of compensation whatsoever. In situations where there is loss of limbs, fingers, broken legs and so on, a certain amount of money is given to injured workers as a form of compensation knowing fully well that they may not be able to carry out such jobs any longer. Workers who also pay the supreme price are also compensated with a sizeable amount of money presented to family of the deceased.

Table 4. Compensation for workers.

\begin{tabular}{lll}
\hline Compensation of workers & frequency & Percentage \\
\hline Yes & 75 & 68.2 \\
No & 35 & 31.8 \\
Total & 110 & 100 \\
\hline
\end{tabular}

Data results in Table 5 reveals that $95(86.4 \%)$ respondents have no provision for clinical services with recognized medical institutions when there is an occurrence of site accidents while $15(13.6 \%)$ have a provisions for clinical services for their site workers. Respondents with provision for clinical services have hospital where they foot medical bills of injured site workers as they are to only report in such places for treatment. Others leave their injured workers to get themselves treated.

Table 5. Other management practices for workers.

\begin{tabular}{llll}
\hline Components & Elements & Frequency & Percentage \\
\hline $\begin{array}{l}\text { Clinical } \\
\text { services }\end{array}$ & $\begin{array}{l}\text { i. } \quad \begin{array}{l}\text { Availability of } \\
\text { clinical services }\end{array} \\
\text { ii. } \begin{array}{l}\text { No provision of } \\
\text { clinical services }\end{array}\end{array}$ & 15 & 13.6 \\
Total & $\begin{array}{l}\text { iii. Detailed records of } \\
\text { reported accident } \\
\text { victims }\end{array}$ & 25 & 86.4 \\
Accident & $\begin{array}{l}\text { iv. No records for } \\
\text { accident victims }\end{array}$ & 85 & 22.7 \\
records & 110 & 77.3 \\
Total & & 110 & 100 \\
\hline
\end{tabular}

Respondents with records of reported accidents discussed that it makes it easy to analyze root causes of accidents thereby advising and also provide necessary equipment to mitigate from source, such causes. These according to them has drastically reduced site accidents rate and also ensured smooth running of construction projects. 

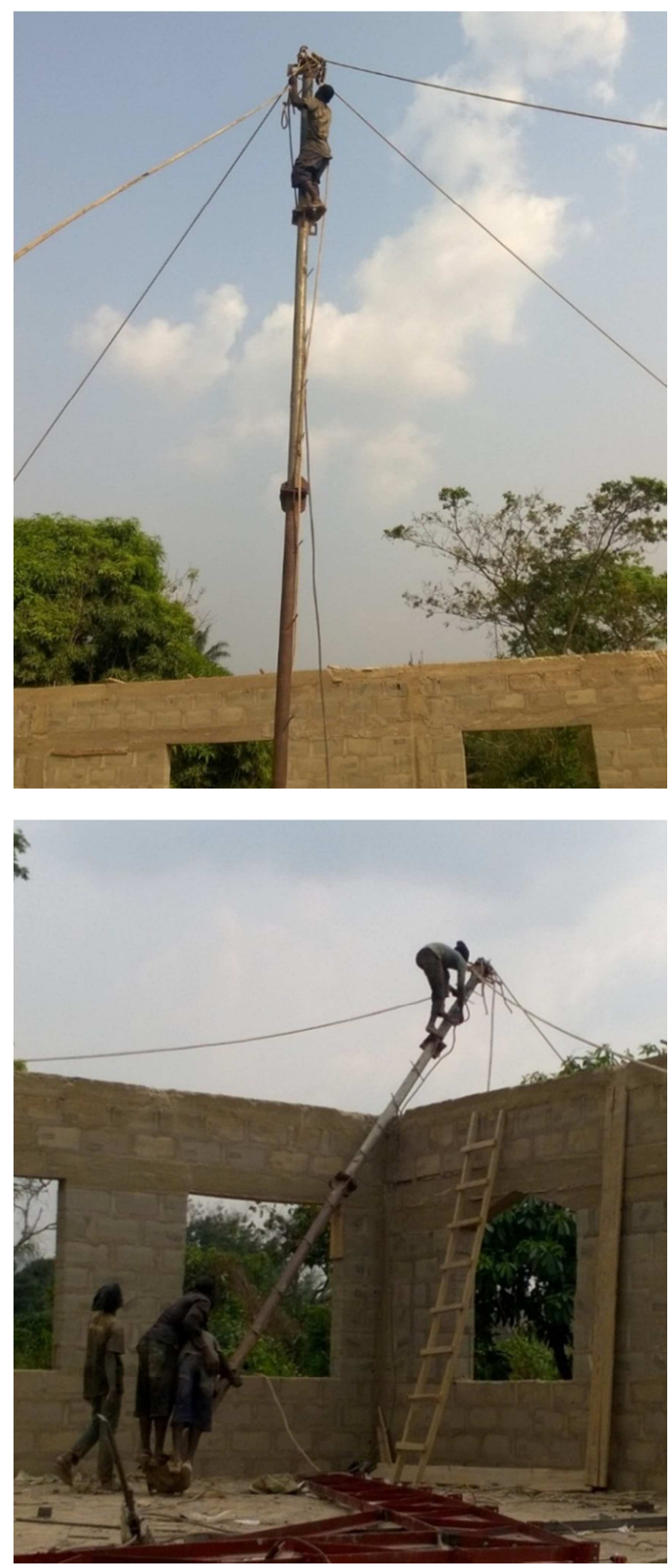

Source: Author's Photograph.

Figure 1. Site worker without personal protective equipment while working at height.

Interview conducted with building construction site workers showed that a large portion of them are not aware of the safety management practices obtainable within their respective companies which in turn make them believe they have to take personal care of themselves when accidents occur. This they further added have made efficiency reduce in that they fear they will be useless to themselves in the end. Some site workers said that they have since taken issues of their safety in their own hands with provision of personal protective equipment (PPE). Another category of site workers revealed that they have often forced themselves to come to site even when ill and also called in sick. This they attributed to the cruel nature of their establishment that refuse to honour sick leave. They often receive deductions from their meagre salaries for failing to show up on site due to reasons pertaining to illness.

\section{Conclusion}

Accidents are unavoidable occurrences on construction site all over the world with a lot of research done on mitigating it from source. The regular practice of safety known to building contractors within the study area is basically provision of personal protective equipment. This is seen from literature as not the only means of mitigating construction site accidents with education and provision of safety signs seeming another possible way out. This paper has carefully examined health and safety management practices in Akure. Professionals in the building industry also compete for and undertake building construction work. It can be observed that the small scale construction industries operate within the confines of their budget because they lack the resources to perform at a high level of health and safety performance. These constraints as regards budgets also tend to prevent such industries from doing a thorough accident reporting. Health and Safety issues are almost never factored in their bidding at the tendering stage thus, making it very difficult in earmarking funds to cater for the events of accidents. Employment of site workers which is predominately casual or daily pay basis provides the building contractor a safe haven when accidents occur. Without employment letters as well as decent contract document which can serve as a legal means of demanding for their rights, these workers are left to cater for themselves and left defenseless. There is also risk of job loss to site workers within the small scale companies when they try to complain or report accident cases.

It can also be seen that few construction companies have a decent level of safety practices captured in their company policies. With the increasing number of small scale construction companies, a lot still needs to be done in mitigating accident causations as the life of construction site workers matter. An area of further study will be to investigate the enforcement of such safety policies whenever there is an unfortunate occurrence of accidents and also seek to build up affordable health and safety practices in small scale enterprises

\section{Recommendation}

To ensure the smooth running as well as timely delivery of building projects, all parties - clients, project managers, Architects, contractors, sub-contractors and artisans must see health and safety as a fundamental issue. The issue of life and its importance must be a key element within the policies of the stakeholders within the industry. Building plans should not be approved without detailed health and safety documents indicating protective equipment provided by companies. Also construction sites where work is carried out must be sealed when there are no provision of safety equipment. At the University level, health and safety issues 
should be included in the curriculum for both undergraduate and postgraduate levels so that they know its importance at the early stages of their training.

\section{References}

[1] Alhajeri, M. (2011). Health and safety in the construction industry: challenges and solutions in the UAE. Unpublished Thesis. Coventry: Coventry University.

[2] Anderson, J. (2007). "Health and safety- matching legislation and enforcement," Proceedings of the Institute of Civil Engineers Management, Procurement and Law, Cambridge Dictionaries Online. Cambridge University Press, pp.11-15.

[3] Awodele, O. A. \& Ayoola, M. C. (2005). An Assessment of Safety Programmes on Construction Sites. Journal of Land Use and Development Studies, 1(1). Retrieved from $\mathrm{http}$ ://journalanduse.org/Assets/Vol.1papers AN ASSESSMENT OF SAFETY PROGRAMMES ON CONSTRUCTIONSITES.pdf

[4] Bala, K., Namala, A. and Adamu, S. (2012). Imperatives of project quality Management plan and Health and Safety plan as Pre-contract documents: Council of Registered Builders of Nigeria and Nigerian Institute of Building Mandatory constructing professional development programme (MCPDP) pp. 511.

[5] Federal Republic of Nigeria, (2010). "The Employee's Compensation Act, 2010," Official Gazette, Abuja, Nigeria, Federal Government Press, 97(101).

[6] HSE (2003). Casual factors in construction accidents.

[7] Idubor, E. E. and Osiamoje, M. D. (2013). “An exploration of health and safety management issues in Nigeria's effort to industrialize," European Scientific Journal, 9(12), pp.154-169.

[8] Indian Council of Medical Research (2003). A National Priority on Occational Health and Safety Management System. Bulletin. Vol. 33, New Delhi, India: Shri J. N. Mathur.

[9] International Labour Office (2005). Prevention: A Global Strategy. Promoting safety and Health at Work. The ILO Report for World Day for Safety and Health at Work, International Labour Office, Geneva, 2005. ISBN 92-2117107-8.

[10] International Training Centre of the ILO (2011). Occupational Safety and Health Management in the Construction Sector. Retrieved from
http://socialprotection.itcilo.org/en/courses/Open courses/A90 4155

[11] Kadiri Z. O, Nden T, Avre G. K, Oladipo T. O, Edom A, Samuel P. O and Ananso G. N (2014). Causes and Effects of Accidents on Construction Sites (A Case Study of Some Selected Construction Firms in Abuja F. C. T Nigeria) IOSR Journal of Mechanical and Civil Engineering (IOSR -JMCE), Vol. 11, pp 66-72.

[12] Mac Collum, D. V (1995). Construction Safety Planning. John Wiley.

[13] Mwobeki, F. K, (2005). Occupational, Health and safety Challenges in construction Sites in Tanzania. $4^{\text {th }}$ Triennial International Conference. Rethinking and Revitalizing construction safety, health, Environmental and Quality, Port Elizabeth. S. A.

[14] Nongiba, A. K. (2008). Impact of health and safety management on safety performance of SMMEs in Ghana.

[15] Occupational Safety and Health Administration (2005). Workers Safety Series (Construction). U.S Department of Labour. U.S.A.

[16] Okeola O. G (2009). Occupational Health and Safety (OHS) assessment in the construction industry. 1st annual civil engineering conference. Physical Planning Unit, University of Ilorin, Nigeria.

[17] Smallwood, J. \& Haupt, T. (2005). The need for construction health and safety (H\&S) and the construction regulations: Engineers' perceptions. Journal of the South African Institution of Civil Engineering, 47(2), pp. 2-8.

[18] Wallah, D. J. (1963). Accident Prevention Manual for shop teacher. The Technical Press Ltd London.

[19] Health and Safety Commission, 1993. Third Report of the Advisory Committee on the Safety of Nuclear Installations Organizing for Safety. ISBN 0-11-882104-0.

[20] Kolo, D. N. (2015). Safety Issues Involving Workers on Building Construction Sites in Nigeria: An Abuja Study. Master's Thesis submitted to the institute of Graduate Studies and Research, Eastern Mediterranean University, North Cyprus.

[21] Balch, A. and Geddes, A. (2003) UK migration policy in light of sectoral dynamics: the case of the construction sector. Unpublished research.

[22] Zou, P. X. W., Zhang, G. and Wang, J. Y. (2007). Understanding the key risks in construction projects in China. International Journal f Project Management. 25(6), 601-614. 